\title{
RHABDOMYOSARCOMA OF BREAST
}

\author{
BY \\ R. WINSTON EVANS \\ From the David Lewis Northern Hospital, Liverpool
}

(RECEIVED FOR PUblication AUGUST 7, 1952)

Rhabdomyosarcoma of the breast is an extremely rare condition. Billroth (1860) described such a tumour in the left breast of a young girl aged 16 years. It was a large unencapsulated neoplasm and was composed of elongated muscle cells with distinct cross-striations and large granular myoblasts. The tumour recurred after local excision. The subsequent history of the patient was not recorded.

Sailer (1937) gave an account of a rhabdomyosarcoma which occurred in the breast of a coloured woman aged 38 years. Local removal of this tumour was also followed by a recurrence lateral to the scar. The patient died shortly afterwards of intestinal obstruction, and at the post-mortem examination rhabdomyosarcomatous deposits were found in the walls of the stomach and jejunum, and of the ileo-caecal valve, causing intussusception. Metastases were also demonstrated in the liver and lungs. Both the breast neoplasm and the visceral tumours were composed of myoblasts with deeply staining nuclei placed centrally and eccentrically in a granular cytoplasm. Occasional elongated, ribbon-like fibres with distinct longitudinal striations were also present. Small polyhedral spindle cells and strands of connective tissue were found interspersed between the muscle cells. Distinct cross-striations were demonstrated in many of the cells.

Govan (1945) described rhabdomyoblastic cells in two mixed malignant tumours of the breast. These cells were mainly of the spindle type. Scattered among these were giant cell forms frequently multinucleated. Some cells were described as strap-shaped, fan-shaped, tadpole-like, or of a modified spider form. In the large cells longitudinal striation was well defined, but cross-striation was limited to beading of the cell margins.

Rhabdomyosarcomata often contain small amounts of fibrous tissue. In some tumours a wellmarked fibrous component may be present, and for this reason they may be easily confused with the fibrosarcomata, especially if reliance is placed entirely on the routine haematoxylin and eosin pre- parations and the more selective staining methods? are neglected. Stout (1946) believes that the rhab-: domyoblastic cells can "assume the guise ando function of fibroblasts," but that the presence of many giant cells, especially monster forms, is $\stackrel{乛}{0}$ evidence that the tumour is not a fibrosarcoma.

Such a rhabdomyosarcomatous neoplasm with? well-developed fibroblastic areas was removed $\vec{z}$ from the left breast of a woman aged 41 years, and it is the purpose of this paper to describe briefly itsbehaviour and to give an account of its histologicale features.

\section{Case Report}

The patient had noticed a small lump in the breasto for three months. At first it appeared to regress, buto during the last 14 days it suddenly grew very rapidly $\stackrel{\perp}{\Omega}$ She then consulted her doctor.

The tumour was situated in the upper and outer? quadrant of the breast. ' It was thought to be a giant fibroadenoma and the left breast was amputated.

Macroscopically it was an ovoid, distinctly lobu lated tumour, apparently clothed by a thin, fibrous capsule. On gross section it was oedematous andmucinous with interspersed firmer, watered-silk-like areas of glistening fibrous tissue. Here and there weren small degenerate cysts full of clear fluid, and smalf areas of reddish discoloration due to haemorrhage. The tumour measured $4 \times 6 \times 12 \mathrm{~cm}$. in its main axes

A forequarter amputation was carried out two and three-quarter years later because of a further growth which had developed in the muscles of the left uppern arm. This was a large circumscribed but nons encapsulated tumour, spheroidal in shape, and measur $N$ ing $8 \times 10 \times 12 \mathrm{~cm}$. in its main diameters. It was of the same general macroscopic character as the originaf growth in the breast. On section it was oedematous? somewhat mucinous, mainly firm in consistency, an of a dull creamy colour speckled by small haemor rhages.

A year later a mass was noticed in the left supraclavicular fossa which was obviously increasing in? size. This mass was treated conservatively, and, as? no biopsy specimen was obtained, its nature musळ్ remain uncertain. General clinical and radiologica evidence of tumour elsewhere. The patient was stilg alive four years after excision of the breast neoplasmo 
The general histological characteristics of the tumour in the breast and of the neoplasm that subsequently developed in the soft tissues of the left arm were identical. Fibroblastic-like cells with acicular nuclei and fibres arranged in bands, often interlacing, were the predominating features, and as a result the tumour was initially diagnosed as a fibrosarcoma (Figs. 1 and 2).

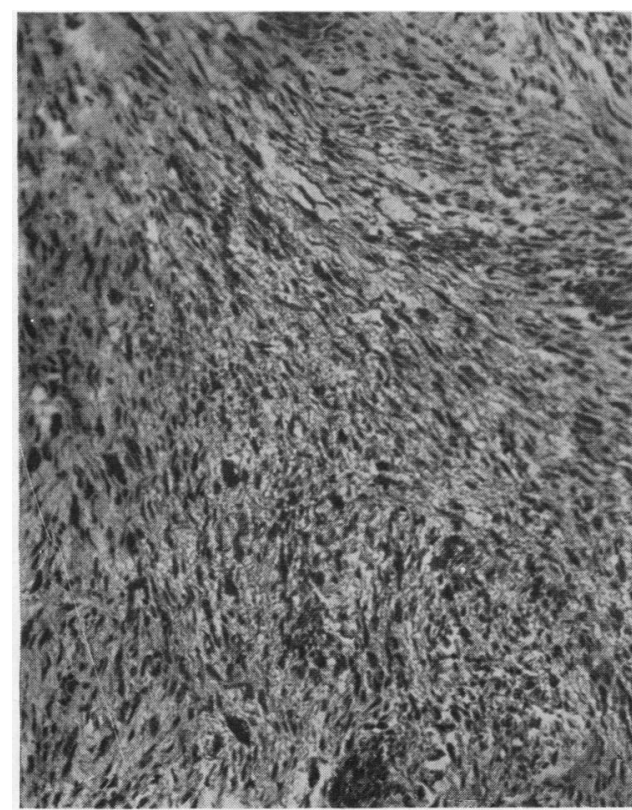

FIG. 1.-Fibrosarcomatous-like pattern showing cells and fibres arranged in bands. Haematoxylin and eosin preparation of the breast tumour $(x 115)$.

Sections stained by Masson's trichrome stain and viewed by a hand lens appeared green, with tracts of red running in all directions. Separating the more cellular tracts were large areas of oedematous tissue and of myxomatous degeneration.

The cytology was pleomorphic. There were long slender cells resembling fibroblasts and accompanied by collagenous and reticulin fibres. Included among these were plump fusiform cells many of which showed mitotic figures (Figs. 3 and 4). Strap cells and giant cells of mono- and syncytial multinucleate forms (Figs. 5 and 6) were also present in moderate numbers. The cytoplasm of these cells was strongly acidophilic, staining red with Masson's trichrome stain. The giant nuclei were of irregular shape, showed a marked affinity for Heidenhain's iron haematoxylin, and displayed considerable mitotic activity often of bizarre type. The nuclei would commonly show a forked extremity.

In the more elliptical cells and in the ribbon-like cells the nuclei were arranged in tandem fashion, and were often eccentrically placed. Some of the elongated fusiform cells presented a fine pericellular pellicle. These cells showed a primitive type of crossstriation (Fig. 7).

Striations were demonstrated by Masson's trichrome stain, phosphotungstic acid haematoxylin, and Heidenhain's iron haematoxylin. Longitudinal fibrillation was very prominent and often ran the whole length of the cell and resulted in a characteristic feathery

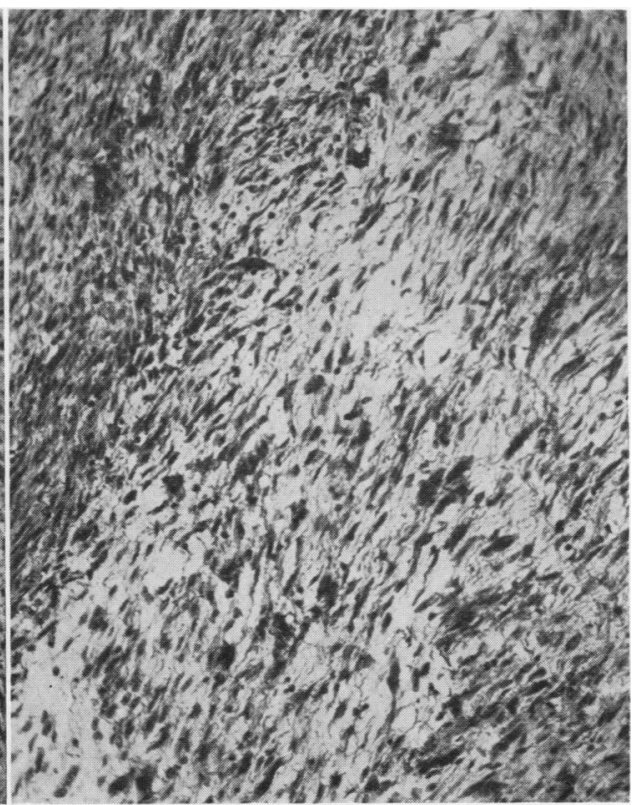

FIG. 2.-A corresponding area from the tumour in the left arm showing alternating bands of cellular and oedematous fibrosarcomatous-like cells and fibres. Haematoxylin and eosin preparation $(x 115)$.

appearance at one or other end of the cell. Frequently the cells would end in a series of fibrillae each showing a prominently beaded appearance (Fig. 5). Primitive cross-striations would take the form of peripheral fine striation or beading or striae running obliquely in partly regimented darkly staining centriole-like bodies (Fig. 7). More definite crossstriation was found after much searching in the Heidenhain's iron-haematoxylin preparations (Fig. 8) to occur in the terminal portions of the plumper spindle cells, and these were often situated in the peripheral zones of the tumours.

There were frequent oedematous areas containing ribbon-like cells with markedly parallel sides. These would show various stages of degeneration and resembled broken and fragmented muscle fibres. Indistinct cross-striations could be made out in some of these fragments even in haematoxylin and eosin preparations (Fig. 9).

Reticulin fibrils were plentiful and were found wrapped around individual cells or running in several directions and surrounding groups of cells. 


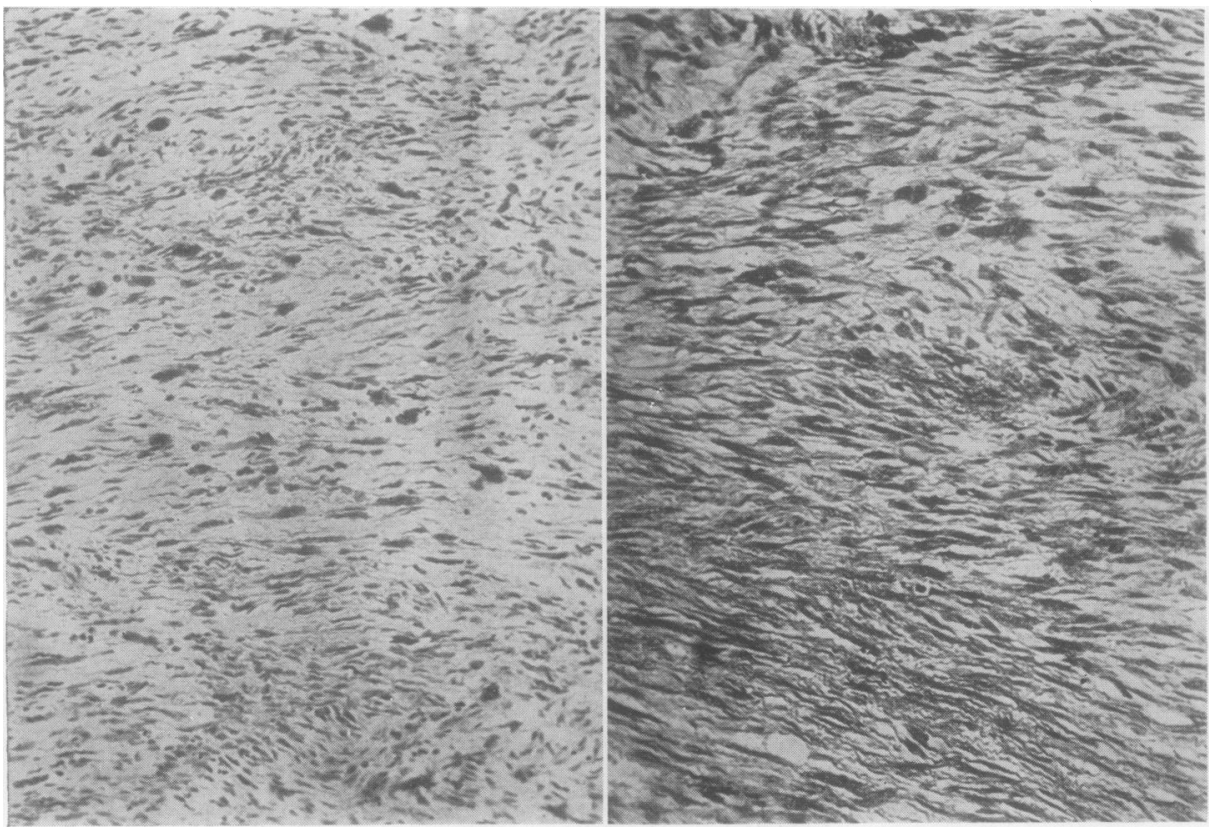

Fic. 3

Fig. 4

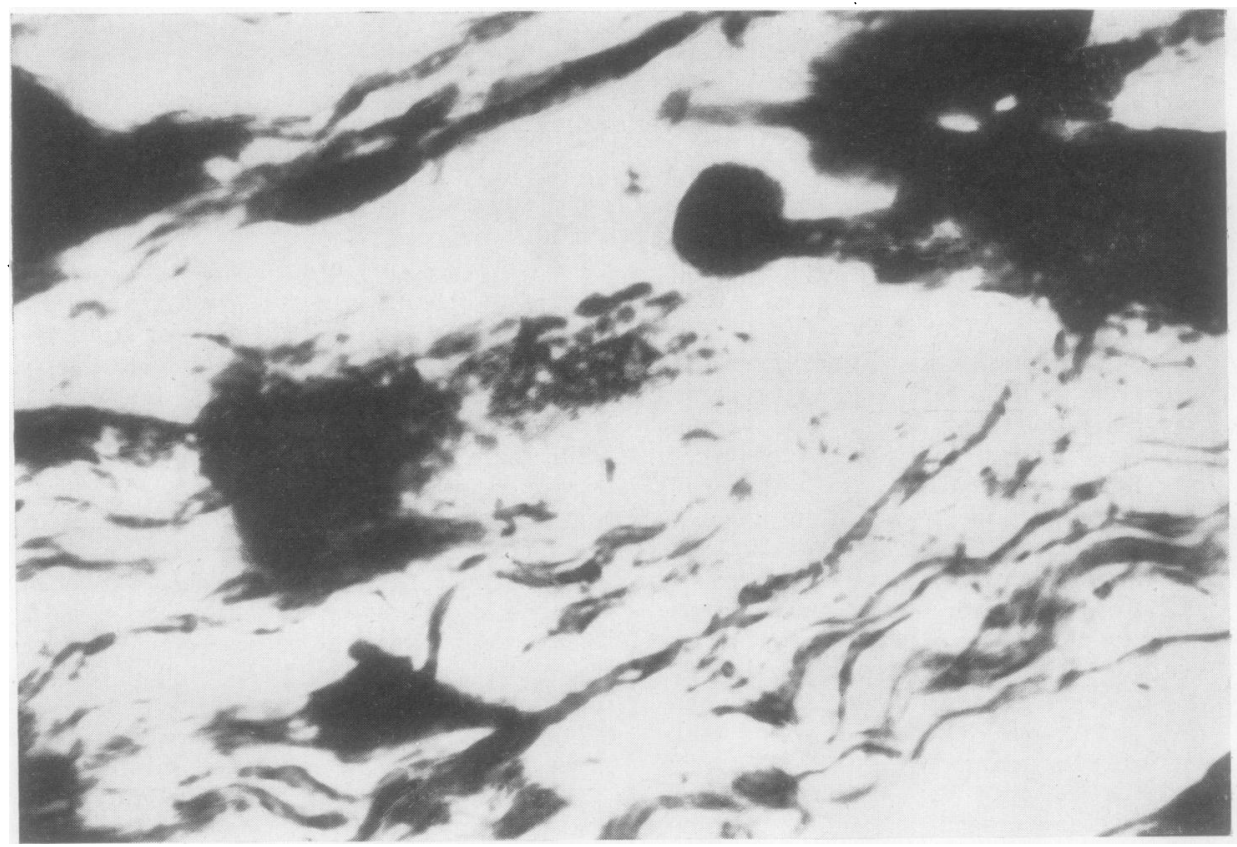

Fig. 5 
Fig. 3.-An area from the breast tumour showing plump ovoid cells interspersed among elongated spindle cells. Haematoxylin and eosin ( $\times 95)$.

Fig. 4.-Corresponding area from tumour in left upper arm. Haematoxylin and eosin $(x$ 115).

Fig. 5.-Irregular-shaped nuclei of strap cells and cytoplasmic longitudinal striations and transverse beading. Heidenhain's haematoxylin $(x 1,200)$.

Fig. 6.-Syncytial giant cells with many vesicular nuclei each with a prominent nucleolus. The cells are lying immediately underneath the thin capsule of the breast tumour. The cytoplasmic prolongations are sharply pointed and forked. Haematoxylin and $\operatorname{cosin}(\times 450)$.

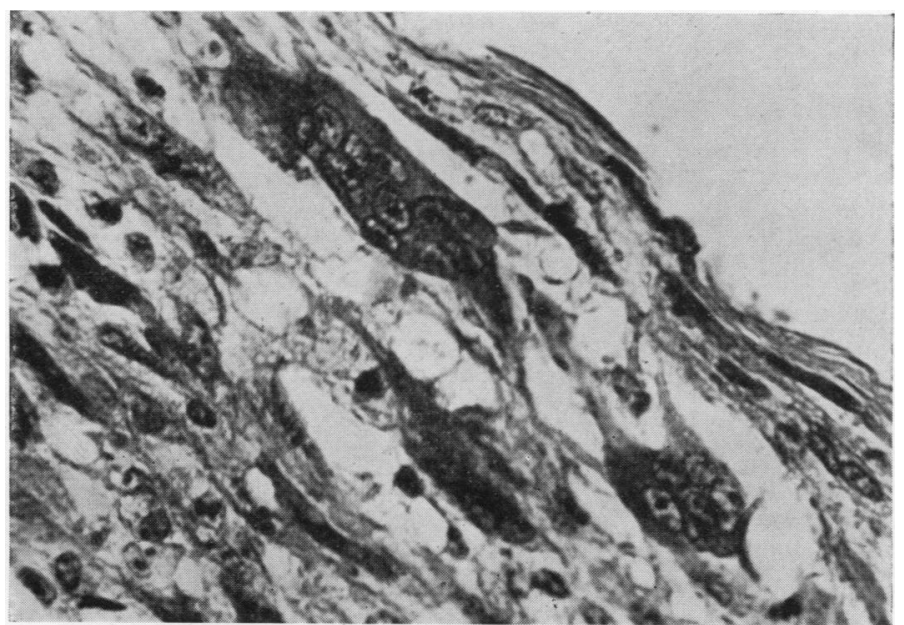

Fig. 6

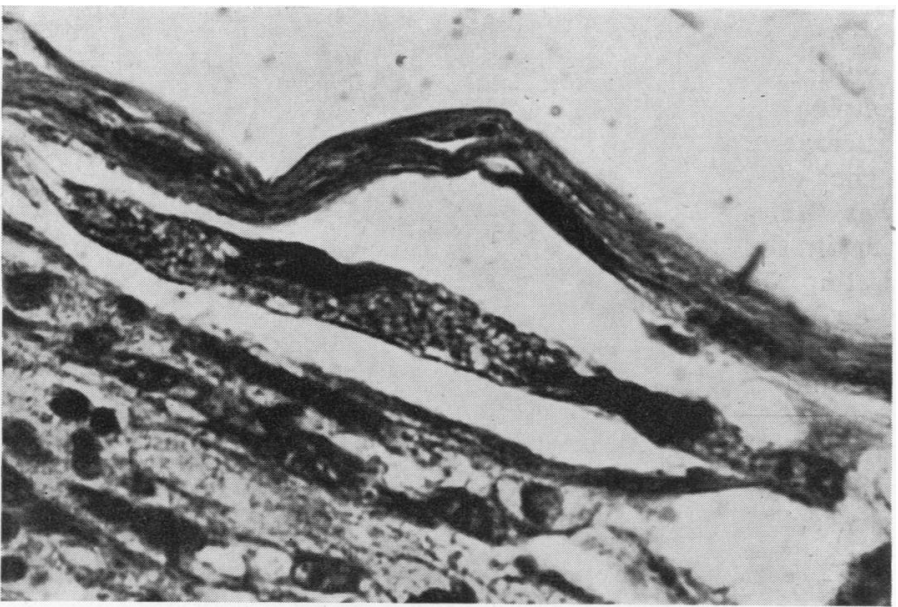

FIG. 7.-An elongated elliptical myoblast with eccentrically placed nuclei exhibiting primitive cross-striation and a very fine pericellular pellicle. Haematoxylin and eosin $(\times 640)$.

FIG. 8.-Iron haematoxylin preparation ( $\times$ 900). Primitive beading and cross-striation are shown in the extremities of the cells.

Fig. 9.-Breast tumour showing area of degenerate and fragmented ribbon-like cells, some showing a faint cross-striation. Haematoxylin and eosin $(x 150)$.

Fio. 7

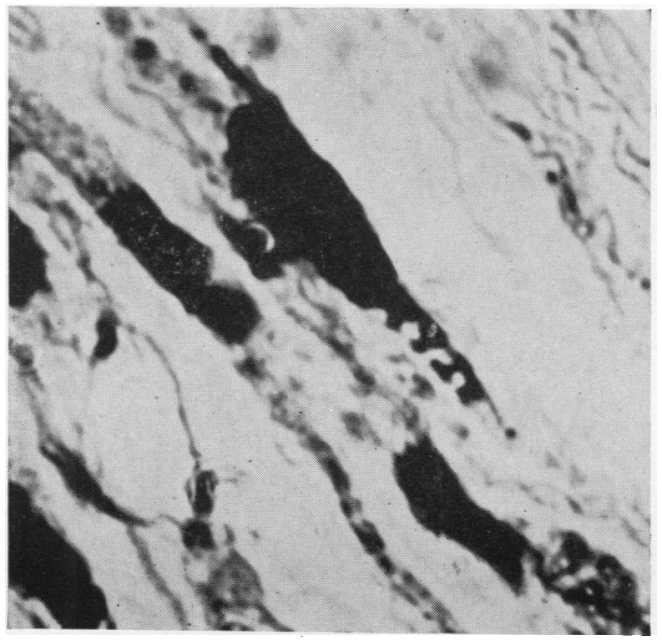

Fı. 8

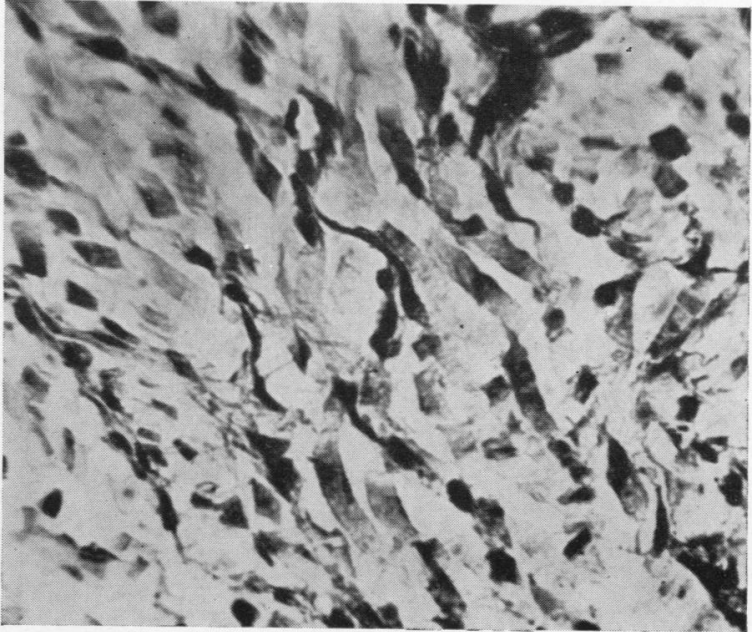

Fro. 9 


\section{Discussion}

The tumour must be regarded as a primary malignant neoplasm arising in the breast. The histological features are certainly suggestive of malignancy. The neoplasm which subsequently developed in the soft tissues of the arm two and three-quarter years later, and which presented identical histological characteristics, was a metastatic deposit. The time interval is too long to entertain the possibility that the breast tumour may have been a metastatic deposit from a primary rhabdomyomatous tumour of the muscles of the upper extremity which remained small and comparatively quiescent and later underwent marked proliferative activity. There was also no direct evidence to suggest this sequence of events.

It would be stretching the long arm of coincidence too far to entertain the possibility that both neoplasms had separate primary origins, one in the breast and the other in the voluntary muscles of the arm. Clinical and radiological examination revealed no possible alternative source for the neoplasms or for the existence of a teratoma. The initial breast tumour was thinly but definitely encapsulated. The tumour in the arm had no such capsule and was infiltrating the surrounding tissues. This is taken to be additional evidence in favour of a primary origin in breast for the rhabdomyosarcomatous tumour.

Sailer (1937) believed that the rhabdomyoblastic tumour of the breast arises from a misplaced mesenchymal " rest." He advanced no evidence in favour of his opinion. When dealing with such a mutable tissue as mesenchyme it is not necessary or wise to explain examples of aberrant differentiation by assuming the existence of developmentally misplaced cellular "rests," especially in an organ such as the breast where mixed tumours occur and the mesenchymal elements of which 으 show great plasticity in producing cartilage, bone, and adipose tissue. It is therefore more reason- $\stackrel{5}{+}$ able to suppose that the rhabdomyoblastic elements are products of differentiation occurring in a tumour of mesenchymal origin.

As Stout (1946) has pointed out, rhabdomyo- $\stackrel{\mathbb{D}}{\Omega}$ blastic cells can imitate the form of fibroblasts and produce collagenous fibres. They have a common origin from primitive mesenchyme and their lines of differentiation are not immutable or at certain levels of development irreversible. The tumour is primarily a neoplasm of undifferentiated mesen- ?요 chymal tissue. Its mode of differentiation is what ${ }^{\circ}$ indicates its specific character.

In various portions of the tumour which have been described areas could be seen, especially in sections stained by Masson's trichrome method, where strap-like muscle cells appeared to be changing into fibroblasts, or, alternatively, fibroblastic cells were developing the staining reactions and fibrillation of muscle cells.

\section{Summary}

The behaviour and histological features of a rhabdomyosarcoma occurring in the breast of a woman aged 41 years are described. A metastatic $\stackrel{0}{\circ}$ deposit appeared two and three-quarter years later $\stackrel{\mathbb{D}}{\circ}$ in the soft tissues of the arm. Histogenesis is $\overrightarrow{0}$ briefly discussed and ascribed to aberrant differentiation of mesenchyme rather than to development in an embryologically misplaced cell "rest."

I am indebted to the late Mr. George Simpson and Mr. J. B. Oldham for access to the case notes.

$$
\begin{aligned}
& \text { References } \\
& \text { Billroth, T. (1860). Virchows Arch. path. Anat., 18, } 69 . \\
& \text { Govan, A. D. T. (1945). J. Path. Bact., 57, 397. } \\
& \text { Sailer, S. (1937). Amer. J. Cancer, 31, 183. } \\
& \text { Stout, A. P. (1946). Ann. Surg., 123, 447. }
\end{aligned}
$$

